Canadian University Music Review

Canadian University Music Review

Revue de musique des universités canadiennes

\title{
Observations sur le développement technique et stylistique de György Ligeti au début des années 1950
}

\section{Friedemann Sallis}

Volume 16, numéro 2, 1996

URI : https://id.erudit.org/iderudit/1014425ar

DOI : https://doi.org/10.7202/1014425ar

Aller au sommaire du numéro

\section{Éditeur(s)}

Canadian University Music Society / Société de musique des universités canadiennes

ISSN

0710-0353 (imprimé)

2291-2436 (numérique)

Découvrir la revue

Citer cet article

Sallis, F. (1996). Observations sur le développement technique et stylistique de György Ligeti au début des années 1950. Canadian University Music Review / Revue de musique des universités canadiennes, 16(2), 44-71.

https://doi.org/10.7202/1014425ar
Résumé de l'article

L'article présente certains aspects de notre thèse de doctorat intitulée « An Introduction to the Early Works of György Ligeti ». Il propose une critique de deux idées reçues et largement répandues dans la littérature sur le musique de ce compositeur : (1) en arrivant en Europe de l'Ouest en décembre 1956, Ligeti se serait départi de tout le bagage technique et stylistique qu'il avait acquis auparavant en Hongrie ; (2) avant de passer à l'Ouest, il n'aurait eu presque aucune connaissance de l'avant-garde musicale de l'Europe de l'Ouest.
All Rights Reserved ( C Canadian University Music Society / Société de musique des universités canadiennes, 1996
Ce document est protégé par la loi sur le droit d'auteur. L'utilisation des services d'Érudit (y compris la reproduction) est assujettie à sa politique d'utilisation que vous pouvez consulter en ligne.

https://apropos.erudit.org/fr/usagers/politique-dutilisation/ 


\title{
OBSERVATIONS SUR LE DÉVELOPPEMENT TECHNIQUE ET STYLISTIQUE DE GYÖRGY LIGETI AU DÉBUT DES ANNÉES 1950
}

\author{
Friedemann Sallis
}

\section{Introduction ${ }^{1}$}

Pince-sans-rire, Hermann Sabbe note que les racines de l'œuvre de György Ligeti ont longtemps été occultées par une apparente rupture dans sa carrière.

C'est comme si cet homme de 35 ans était tombé du ciel dans le paysage musical de l'Europe de l'Ouest. Comme si quelqu'un avait fait une apparition. Quelqu'un dont le seul terrain culturel serait réduit à des expériences électroacoustiques $^{2}$.

La littérature sur Ligeti est fortement marquée par deux idées reçues interdépendantes qui renforcent cette impression de rupture. Premièrement, en quittant la Hongrie en décembre 1956, Ligeti se serait départi de tout le bagage technique et stylistique qu'il avait acquis auparavant. Dans sa thèse sur des œuvres écrites par Ligeti pendant les années 60 (la première étude sérieuse sur son œuvre), Erkki Salmenharra dresse un parallèle quelque peu forcé entre Ligeti et Edgard Varèse. En passant à l'Ouest, Ligeti aurait rompu tout lien avec son passé comme l'aurait fait Varèse en émigrant en Amérique ${ }^{3}$. Dans la troisième édition de Moderne Musik, 1945-1965 d'Ulrich Dibelius (un survol de l'avant-garde des années 50, omniprésent dans l'espace culturel germanophone), on peut lire que, pour Ligeti, l'émigration signifiait une coupure claire et nette à tous les égards ${ }^{4}$. Paul Griffiths, dans la première monographie en

1Nous remercions chaleureusement Paul Castonguay, Jean-Paul Darmsteter, Christiane Parchet, Robert Piencikowski et Georges Starobinski pour les corrections qu'ils ont apportées à ce texte qui n'est pas écrit dans notre langue maternelle.

2 «s war, als ob der etwa 35jährige aus heiterem Himmel in die westeuropäische Landschaft herabgestiegen wäre. Als ob da einer Apparition gemacht hätte. Einer, dessen Nährboden auf die Erfahrungen im elektronischen Studio eingeschränkt war. » Herman Sabbe, « György Ligeti : Studien zur kompositorischen Phänomenologie », dans Musik-Konzepte, vol. 53, éd. par Heinz-Klaus Metzger et Rainer Riehn (Munich : edition text + kritik, 1987), 104.

3Erkki Salmenhaara, Das musikalische Material und seine Behandlung in den Werken Apparitions, Atmosphères, Aventures und Requiem von György Ligeti (Helsinki : Acta Musicologica Fennica, 1969), 27. Ne serait-ce que pour des raisons gégraphiques et culturelles, la comparaison entre le déménagement de Varèse de Berlin a New York (via Paris) et l'émigration de Ligeti de Budapest à Vienne semble boiteuse.

4Ulrich Dibelius, Moderne Musik, 1945-1965 (Münich : R. Piper, 1984), 185. Récidiviste, Dibelius insiste sur ce point dans son récent ouvrage György Ligeti : eine Monographie in Essays (Mayence : Schott, 1994), 9-10. 
langue anglaise sur Ligeti, écrit qu'en arrivant à l'Ouest le compositeur, à l'âge de 35 ans, est devenu soudain « le vrai Ligeti »5. Plus récemment encore, Elmar Budde publiait un article dans lequel il considère que les premières compositions sont celles écrites entre Atmosphères (1961) et Moment, Portrait, Bewegung (1976). La centaine de compositions écrites durant les années 40 et 50, y compris le Quatuor à cordes $n^{0} 1$ et Apparitions, est complètement passée sous silence ${ }^{6}$.

Deuxièmement, avant de passer en Occident, Ligeti n'aurait eu presque aucune connaissance de l'avant-garde musicale de l'Europe de l'Ouest. Cette idée est inexacte. L'anecdote - inventée de toutes pièces - selon laquelle Ligeti, en 1957, aurait vu par hasard pour la première fois les Structures I de Pierre Boulez chez Karlheinz Stockhausen, a largement contribué à répandre cette idée ${ }^{7}$. Dans un entretien avec Pierre Michel, Ligeti a affirmé qu'avant la révolution hongroise, il avait reçu une copie de l'œuvre dans un lot de partitions et de livres envoyé par Universal Edition ${ }^{8}$. Quoi qu'il en soit, l'idée que Ligeti se serait présenté comme une sorte de feuille vierge est fortement enracinée dans notre compréhension de son développement ${ }^{9}$. Pour preuve, Jonathan Bernard s'étonne qu'entre 1957 et 1958 Ligeti ait pu produire autant en si peu de temps.

Bien qu'il avait à peine quelques connaissances de la technique dodécaphonique, sans parler de l'extension de celle-ci aux paramètres autres que la hauteur, moins de trois ans ont passé avant que Ligeti ne commence déjà à coucher par écrit ses critiques des techniques sérielles, telles qu'elles étaient appliquées au cours des années $1950^{10}$.

Effectivement, entre janvier 1957 et décembre 1958, Ligeti a :

(1) maîtrisé suffisamment d'aspects de la musique électro-acoustique pour pouvoir réaliser deux compositions, dont Artikulation, créée le 25 mars 1958 ;

(2) composé une première version d'Apparitions et en a entrepris la version finale, terminée en $1959^{11}$;

5Paul Griffiths, György Ligeti (Londres : Robson Books, 1983), 14.

6Elmar Budde, * Musik - Klang - Farbe : zum Problem der Synästhesie in den frühen Kompositionen Ligetis », dans György Ligeti : Personalstil - Avantgardismus - Popularität, éd. par Otto Kolleritsch (Vienne : Universal Edition, 1987), 56.

7Ove Nordwall, György Ligeti : eine Monographie (Mayence : Schott, 1971), 63.

8 Pierre Michel, György Ligeti, compositeur d'aujourd'hui (Paris : Minerve, 1985), 138.

9Notons que Ligeti lui-même a sporadiquement contribué à l'établissement de cette idée. György Ligeti, « Auswirkungen der electronische Musik auf mein kompositorisches Schaffen », cité dans Michel, György Ligeti, 30.

10 « Although he had arrived with scarcely any knowledge of twelve-tone technique, let alone the extension of serial principles to aspects of musical sound other than pitch, not even three years had passed before Ligeti was setting down his criticisms of serial techniques as they had come to be applied to composition during the 1950's. » Jonathan W. Bernard, "Inaudible Structures, Audible Music ; Ligeti's Problem and His Solution ", Music Analysis 6, $\mathrm{n}^{\circ} 3$ (1987) : 207.

11 Apparitions pour orchestre (1957), deuxième version, inachevé (collection György Ligeti, Fondation Paul Sacher, Bâle, Suisse). La Fondation Sacher possède une mise au net de 27 pages de cette version. 
(3) révisé la dernière section de son Quatuor à cordes $n^{\circ} 1$ (mes. 1059-207) et en a préparé le matériel pour la création le 8 mai 1958 à Vienne ;

(4) publié deux analyses en langue allemande ${ }^{12}$ : «Bartóks fünftes Streichquartett : Einführung und Formanalyse », dans Béla Bartók, Streichquartett $V$ (Vienne : Universal Edition, 1957) ; « Pierre Boulez : Entscheidung und Automatik in der Structure Ia », Die Reihe, $n^{\circ} 4$ (1958): 33-63.

(5) écrit «Wandlungen der musikalischen Form » en novembre et décembre 1958, ce qui suppose qu'il avait pu assimiler la Philosophie der neuen Musik de Theodor W. Adorno, pour ne mentionner qu'un des titres cités dans cet important article.

Que Ligeti ait pu accomplir tout cela sans préparation préalable semble pour le moins fantaisiste compte tenu de sa situation précaire en tant que réfugié politique et compositeur encore obscur ${ }^{13}$.

Carl Dahlhaus met en garde contre le fait de croire trop rapidement aux liens apparemment évidents entre l'œuvre d'un compositeur et sa biographie ${ }^{14}$. Non qu'il y ait absence de liens, mais ceux-ci sont souvent indirects et ambigus. À cet égard, les liens entre l'œuvre et la biographie du jeune Ligeti sont paradigmatiques de ce type de relation. Bien entendu, d'un point de vue biographique, l'émigration de Ligeti, survenue après l'écrasement de la révolution hongroise, représente un événement décisif dans sa vie comme dans celle de tant d'autres Hongrois de cette période. D'autre part, le fait que 1956 serve à délimiter ce qu'on appelle l'œuvre de jeunesse indique qu'au moins à première vue, cette date possède une signification réelle pour le développement du compositeur. $\mathrm{Par}$ contre, il serait erroné de prétendre que l'émigration suppose automatiquement une rupture dans son développement en tant que compositeur ou dans son œuvre même.

Dans le présent article, nous cherchons à démontrer qu'au début des années 50 , l'évolution de Ligeti, bien qu'entièrement fondée sur l'héritage bartókien, est fécondée par une réflexion soutenue sur la pensée musicale de la Deuxième école de Vienne. Un article de Ligeti intitulé « Megjegyzések a bartóki kromatika kialakulásák egyes feltételeiről » [Remarques sur les conditions du développement du chromatisme bartókien], publié à Budapest en 1955, permet d'étayer

12Ligeti possédait une excellente connaissance de l'allemand. Néanmoins, pour établir des documents en vue de publication dans une autre langue que la sienne, il faut forcément plus de temps.

13Bien sûr, il ne s'agit pas de contredire l'affirmation, maintes fois répétée par le compositeur, que la Hongrie, comme les autres pays du bloc de l'Est, était isolée de l'Ouest. Comme ses collègues du monde artistique et intellectuel ainsi que le reste de la population, Ligeti subissait les conséquences d'un des régimes staliniens les plus répressifs de l'époque. Néanmoins, cet isolement n'a jamais été total. L'information arrivait à filtrer. Or, cette situation, particulièrement en ce qui concerne la méthode dodécaphonique, n'a jamais empêché Ligeti de réfléchir ; elle semble même l'y avoir stimulé. Si l'information dont il disposait sur l'avant-garde de l'Ouest était incomplète, Ligeti n'en avait pas moins une connaissance qui lui permettait de se forger sa propre opinion.

14Carl Dahlhaus, Ludwig van Beethoven und seine Zeit (Laaber : Laaber Verlag, 1987), 29-30. 
cette affirmation ${ }^{15}$. Il cherche à montrer que la tonalité chromatique de Bartók découle d'une résolution dialectique du conflit entre la tonalité traditionnelle et la méthode dodécaphonique de Schönberg. C'est précisément dans sa critique de cette méthode que Ligeti dévoile pour la première fois les prémisses d'un concept musical à partir duquel vont éclore des œuvres telles qu'Apparitions et Atmosphères.

Notre article comprend deux sections. La première expose les sources de l'œuvre de jeunesse de Ligeti, une production qui reste encore méconnue malgré l'importance du compositeur. La deuxième section analyse le contenu du texte « Megjegyzések a bartóki kromatika kialakulásák egyes feltételeiről ». Afin d'en mieux saisir la signification, nous présentons le contenu tiré d'articles antérieurs et ultérieurs ainsi que des observations techniques sur certaines œuvres écrites entre 1953 et 1961 . Le but de ce travail est d'abord historique ${ }^{16}$. Nous cherchons à présenter des notions et des techniques qui ont contribué à l'éclosion d'une des figures les plus originales de la deuxième moitié du $\mathrm{XX}^{\mathrm{e}}$ siècle de manière à combler une lacune dans les connaissances relatives au compositeur et à ouvrir une nouvelle perspective sur l'histoire de la musique des années 50.

\section{Sources}

Avant son émigration, Ligeti a écrit au moins 114 œuvres ${ }^{17}$. Le lecteur en trouvera en appendice 1 la liste, tirée d'un catalogue d'œuvres de jeunesse de Ligeti préparé par nous-mêmes. Ce catalogue est une révision complète des catalogues I et II de l'ouvrage de Nordwall, catalogues qui depuis plus de 20 ans constituent les seules sources d'information valables sur ce répertoire.

Les sources principales des catalogues de Nordwall étaient les œuvres ellesmêmes, conservées sous forme de manuscrits (esquisses, brouillons ou copies définitives), de partitions publiées (entre 1942 et 1956, 18 compositions ont été éditées en Hongrie, en Roumanie et en Angleterre) et de photocopies. Ces documents sont regroupés principalement en trois endroits : au domicile du compositeur, à la Fondation Paul Sacher à Bâle ${ }^{18}$ et, en ce qui concerne les compositions publiées avant 1956, à la Bibliothèque nationale de Hongrie à Budapest. Il faut ajouter à ces sources huit cahiers datés de 1941 à 1952 et qui contiennent des œuvres mises au net, des esquisses et des fragments d'œuvres inachevées ainsi que des exercices de composition. Six d'entre eux se trouvent actuellement à la Fondation Sacher tandis que les deux autres appartiennent

15 György Ligeti, « Megjegyzések a bartóki kromatika kialakulásának egyes feltételeirōl " [Remarques sur les conditions du développement du chromaticisme bartókien], $U_{j}$ zene szemle $6, \mathrm{n}^{\circ} 9$ (1955) : 41-44.

16Il y a 10 ans, Dahlhaus, Die Musik der fünfziger Jahre : Versuch einer Revision, ed. par Carl Dahlhaus, Veröffentlichung des Instituts für Neue Musik und Musikerziehung Darmstadt, vol. 26 (Mayence : Schott, 1985), 7, déclarait que les années 50 faisaient désormais partie de l'histoire.

17 Ce chiffre, établi au meilleur de nos connaissances au début des années 90 , ne peut être considéré comme définitif; il s'approche néanmoins fort problablement de la vérité.

18 Vers la fin des années 80 la Fondation Paul Sacher a acheté la collection de documents appartenant à Ove Nordwall. 
encore au compositeur. Outre ces documents, les catalogues de Nordwall ont été élaborés à partir des sources suivantes :

(1) Soixante-douze fiches en papier jaune qui faisaient partie de deux catalogues d'œuvres que Ligeti a tenus du début des années 40 jusqu'au début des années 50. Elles ont été retrouvées par Nordwall dans une armoire chez Ligeti à Vienne en 1969. Les fiches encore existantes contiennent des informations sur les œuvres datées de 1943 à 1952. Sur chaque fiche, le compositeur avait soigneusement noté à la main le titre, la date de composition et d'autres renseignements concernant la publication, la création et même la date et le lieu de concerts ultérieurs. L'énumération invite à penser que les fiches faisaient partie de deux catalogues séparés; elle indique aussi qu'une partie de ces catalogues personnels a été perdue.

(2) Curriculum vitæ préparé vers la fin de 1956 pour John S. Weissmann, imprésario et critique musical d'origine hongroise vivant à Londres. Le curriculum vitæ contient une liste d'œuvres répertoriées par genre : piano solo, piano à quatre mains, orgue, violoncelle solo, mélodies pour voix et piano, musique de chambre, musique d'orchestre, musique chorale a cappella, musique pour chœur et orchestre et musique de scène.

(3) Liste d'œuvres dressée par Ligeti pour Nordwall en 1963.

À ces trois sources, conservées aujourd'hui à la Fondation Paul Sacher, se sont ajoutées deux nouveaux documents qui ont rendu possible une révision en profondeur des catalogues de Nordwall et ainsi permis la correction de nombreuses imprécisions et erreurs.

(1) La liste d'œuvres tenue par la Magyar zenemủvészek szövetsége [Association des musiciens hongrois]. Cette liste, dans laquelle figurent 73 titres datant de 1941 à 1956, présente les œuvres de Ligeti officiellement reconnues par l'État. Comme les fiches mentionnées plus haut, elle contient le titre, la date de composition ainsi que des renseignements sur la création et la publication de l'œuvre en question. Elle couvre tous les aspects de l'activité du compositeur et contredit ainsi quelques idées reçues concernant certaines œuvres écrites durant les années 50. Nordwall écrit par exemple que des œuvres comme Musica ricercata et les Six bagatelles pour quintette à vent, qui comptent parmi les plus intéressantes composées entre 1950 et 1956, sont restées des « fonds de tiroirs » ${ }^{19}$. Au sujet des mêmes œuvres, Michel parle de «compositions secrètes ${ }^{20}$. En fait, toutes ces œuvres ont été tôt ou tard inscrites auprès des autorités. Évidemment, cela ne signifie pas pour autant qu'elles auraient pu être jouées dans un concert public. Nordwall peut donc avec raison parler d'œuvres de tiroir (dans ce cas, le 
tiroir semble avoir été celui de la bureaucratie). Par contre, parler de compositions secrètes est un véritable non-sens.

(2) Lettre d'introduction de Ligeti à John S. Weissmann écrite à Vienne le 25 janvier 1957. Cette lettre contient les mêmes titres que le curriculum vitæ préparé pour Weissmann. De plus, le compositeur a ajouté des commentaires personnels ainsi que des jugements sur l'importance de certaines œuvres. Nous sommes donc en présence d'une sorte d'autoportrait du jeune compositeur au moment même de son arrivée à l'Ouest.

L'œuvre de jeunesse de Ligeti est large dans le sens qu'il touche à tous les genres. De la grande œuvre pour solistes, chœur et orchestre, à la pièce pour instrument seul, en passant par la musique de scène, le jeune Ligeti s'est bâti une solide compétence durant ses années de formation.

D'un point de vue purement quantitatif, ce sont les œuvres vocales qui dominent. Sur 114 compositions, plus de la moitié, c'est-à-dire 60, sont écrites pour voix solo, ensemble de solistes ou pour chœurs divers avec ou sans accompagnement. De cette production vocale, c'est la musique chorale a cappella (32 compositions) qui domine. Elle constitue le plus grand sous-ensemble parmi les œuvres de jeunesse de Ligeti. Le deuxième sous-ensemble de ce répertoire est - en importance quantitative - la musique pour piano solo.

Bien sûr, l'importance d'un genre ne peut être évaluée seulement de façon quantitative. Le quatuor à cordes et la mélodie pour voix et piano sont deux genres importants malgré le nombre relativement restreint de compositions abouties. Entre 1938 et 1954, Ligeti a composé quatre quatuors à cordes. À chaque fois l'œuvre constitue une épreuve qui indique le stade du développement technique et stylistique du jeune compositeur. En ce qui concerne les mélodies pour voix et piano, Ligeti a produit trois petits cycles sur des textes de Sándor Weöres, Attila Jósef et János Arany. Du point de vue stylistique, les deux derniers cycles sont issus directement de l'héritage de Bartók et Kodály ; aussi témoignent-ils de l'appartenance de Ligeti à la Nouvelle école hongroise ${ }^{21}$. (Cette appartenance aura des conséquences stylistiques importantes surtout durant les études à Budapest, c'est-à-dire de 1945 à 1949.) Les cycles prouvent aussi que les œuvres directement liées à cette école ne sont pas forcément que des adaptations folkloriques mineures.

\section{Entre Bartók et Schönberg}

Entre 1948 et 1956, Ligeti publie 18 documents en tant que journaliste, critique et pédagogue ${ }^{22}$. On en trouvera la liste complète à l'appendice 2 . Le dernier article publié en Hongrie, intitulé « Megjegyzések a bartóki kromatika

21 Dans sa première contribution journalistique pour la revue allemande Melos, Ligeti brosse une brève description des caractéristiques stylistiques de cette école; voir « Neue Musik in Ungarn », Melos $16, \mathrm{n}^{\circ} 1(1949): 5-6$.

22Pour une description globale de ses documents voir Friedemann Sallis, « 1950 - un tournant décisif pour György Ligeti ? », Contrechamps, $\mathrm{n}^{\mathrm{os}} 12 / 13$ (1990) : 15-18. 
kialakulásának egyes feltételeiről », est sans doute l'un des plus importants de cette série.

Lu au premier degré, « Megjegyzések » est une défense vigoureuse des travaux d'Ernő Lendvai sur le style bartókien, qui avaient été reçus de façon très négative par les milieux officiels ${ }^{23}$. Ligeti connaissait Lendvai depuis ses années d'études à l'Académie Franz Liszt de Budapest ; les deux hommes fréquentaient le cours d'analyse de Bence Szabolcsi24. Dans sa défense de l'ouvrage de Lendvai, Ligeti n'a pas hésité à avancer des arguments qui ne relevaient pas de l'orthodoxie officielle. Pour preuve, notons les précautions prises par l'éditeur de la revue ; dans une annotation, ce dernier a cru bon de faire la remarque suivante : « Ce commentaire remarquable sur la musique de Bartók doit être compris, pour le moment, comme matière à discussion préliminaire ${ }^{25}$. 》

Dans le contexte des écrits de Ligeti, «Megjegyzések » propose une première réponse à une question posée huit ans plus tôt dans un article pour la revue Melos intitulé « Neues aus Budapest : Zwölftonmusik oder " Neue Tonalität"? ". Cette interrogation trahit un éveil de curiosité pour la pensée musicale de la Deuxième école de Vienne, ce sur quoi nous reviendrons. Ce qui nous intéresse pour le moment est la critique de la musique dodécaphonique qui se trouve dans « Megjegyzések ». Celle-ci peut être résumée en trois points.

D'abord, Ligeti affirme qu'une des implications de la méthode dodécaphonique est une tendance au nivellement du contraste musical.

La construction harmonique la plus variée a détruit la construction harmonique comme telle : le monde sonore le plus riche aboutit à un appauvrissement sonore complet ; il n'y a ni attraction, ni résolution dans la technique dođécaphonique, ni consonance, ni dissonance (sûrement ces termes n'ont de sens qu'en relation l'un à l' autre); la musique s'embrase toujours à la même température élevée ; elle présente les mêmes nuances des mêmes couleurs. La possibilité de contraste ne réside que dans le rythme, dans l'intensité ou dans l'orchestration. Cependant, même ces possibilités de variation, qui ont survécu à Schönberg, disparaissent chez les compositeurs qui ont étendu avec une rigueur extrême la technique sérielle au rythme, à l'intensité et à l'orchestration (voir Boulez) ${ }^{26}$.

23Ernō Lendvai, Bartók stílus a * Szonata két zongorára és ütohangszerekre * és * Zene húros-, ütohangszerekre és celestára » tükrében [Le style de Bartók vu dans la «Sonate pour deux pianos et percussion » et « Musique pour instruments à cordes, percussion et celesta »] (Budapest : Zenemükiad6, 1955).

24György Kurtág, « Meine Begegnung mit György Ligeti », dans Ligeti und Kurtág in Salzburg, éd. par Ulrich Dibelius (Zurich : Palladion, 1993), 71.

25 « Bartók zenéjének ez az érdekes magyarázata egyelöre vitaanyagnak tekintendũ. (Szerk.) ». Ligeti, « Megjegyzések », 44 (les traductions sont de l'auteur du présent article).

26 « A legsokrétübb akkordépítkezés megsemmisítette az akkordépítkezést, mint olyant ; a leggazdagabb hangzásvilág a hangzás teljes elszegényedéséhez vezetett ; a dodekafoniában nincs vonzás, oldódás, nincs konszonancia és disszonancia (hiszen ezeknek csak egymáshoz viszonyítva van értelmük), a zene álladóan azonos höfokon izzik, azonos színek azonos árnyalatait sorakoztatja fel. Kontrasztlehetöségeket már csak a ritmika, dinamika és hangszerelés ad, de ez a még Schönbergnél megmaradt változatosság is eltünik a sortechnikát végsõ következetességgel a ritmikára, dinamikára és hangszerelésre is kiterjesztô szerzōknél (pl. Boulez-nél). » Ligeti, « Megjegyzések », 43. 
Ensuite, une des conséquences de la méthode dodécaphonique est une dissociation entre le temps et le phénomène sonore.

Dans une composition dodécaphonique « haut et bas » et « avant et après » sont nécessairement interchangeables [...] L'écoulement du temps musical devient problématique : il n'y a plus de développement, la forme devient statique, à toutes fins utiles, elle se situe en dehors du temps ${ }^{27}$.

Enfin, Ligeti prédit la dissolution de la méthode dodécaphonique qui fera suite à l'inexorable marche de l'histoire.

Comme le germe de l'autodestruction était contenu dans le système diatonique, le dodécaphonisme porte en lui sa propre fin : si on noue plusieurs voix dodécaphoniques en une unité contrapuntique, il est inévitable que certaines notes qui apparaissent dans une voix réapparaissent dans une autre plus tôt que prévu par la série [...] La polyphonie dérange la logique sérielle stricte, la composition dodécaphonique s' autodétruit ${ }^{28}$.

Cette critique faite, une question se pose : quelles sources ont nourri la réflexion de Ligeti ? Il faut revenir avant tout à l'entourage de Ligeti à l'Académie Franz Liszt, et notamment à son professeur de composition, Sándor Veress. C'est entre 1945 et 1949 que ce dernier commence à étudier la musique de Schönberg et de sa méthode 29 , et c'est justement durant cette période que Ligeti fait partie de sa classe de composition. C'est d'ailleurs au même moment que Ligeti rédige l'article intitulé « Neues aus Budapest : Zwölftonmusik oder "Neue Tonalität" ? ", dans lequel nous relèverons deux points. D'une part, Ligeti déplore le fait que la seule œuvre de Schönberg jouée durant la saison 1947-48 à Budapest ait été Verklärte Nacht, œuvre peu typique qui présente une image fausse du compositeur autrichien ${ }^{30}$. Une telle observation suppose que l'auteur s'imagine en possession d'une image juste. D'autre part, bien qu'en 1948 la scène musicale à Budapest ait été fortement marquée par la polémique autour de l'article de René Leibowitz, dans lequel Bartók est sévèrement critiqué pour n'avoir pas suivi Schönberg ${ }^{31}$, Ligeti tente de rester au-dessus de la mêlée.

27 « Tehát a dodekafon szerkesztésben szükségképpen felcserélhetõ a fent és lent, a késõbb és az elöbb, így a sorok négyféleképpen jelentkeznek [...] Ezzel problematikussá vált a zene idöbeli lefolyása : nincs többé fejlesztés, a formálás statikussá, mintegy idōn kívülivé válik. » Ibid.

28 « Ahogy a diatonia csírajában tartalmazta felbomlásának lehetôségét, a dodekafonia is magában hordja megszünését : ha több dodekafon szólamot kontrapunktikus egységbe szövünk, elkerülhetetlen, hogy az egyik szólamban szereplö egyes hangok ne kerüljenek az elöirtnál hamarabb sorra egy másik szólamban [...] A többszólamúság megbontja a szigorí sorlogikát, a sorszerkesztés megsemmisíti önmmagát. » Ibid., 43-44.

29Sándor Veress, cité dans Andreas Traub, "Sándor Veress, Lebensweg - Schaffensweg 》, dans Sándor Veress Festschrift zum 80. Geburtstag (Berlin : Haseloff, 1986), 30. Il faut aussi noter qu'après son départ définitif de la Hongrie en 1949, Veress se toumera de façon décisive vers la technique dodecaphonique pour réviser et réorienter sa technique de composition. Dès 1952 il terminera sa première composition majeure basée largement sur la méthode de Schönberg ; son Concerto pour piano, cordes et percussion. Évidemment, une telle réorientation ne se fera pas sans préparation, et de surcroît, s'avèrera difficile pour le réfugié politique à l'avenir incertain.

30Ligeti, «Zwölftonmusik oder " Neue Tonalität" ? », Melos 17, n² 2 (1950) : 46.

31 Selon Leibowitz, « Béla Bartók ou la possibilité du compromis dans la musique contemporaine », 
Il prône une sorte de coexistence entre les adhérents des diverses écoles, notamment ceux de la Deuxième école de Vienne et de la Nouvelle école hongroise. Selon Ligeti la nouvelle musique doit être aussi diverse que possible. Elle doit contenir des difficultés qui suscitent la discussion, laquelle ne peut être que fructueuse ${ }^{32}$.

Ce plaidoyer pour la pluralité musicale (dans lequel nous entendons immanquablement une résistance contre le réalisme socialiste qu'on imposait en Hongrie à cette époque) marque le début d'un processus qui amènera Ligeti à prendre peu à peu ses distances vis-à-vis de la Nouvelle école hongroise. En 1954, dans une critique de la Szonatina pour flûte et piano de Pál Járdányi, Ligeti notera, de façon désabusée, que la beauté simpliste de l'harmonie et de la mélodie sont des caractéristiques bien connues du « nouveau style hongrois » 33 . Plus tard, dans une lettre écrite à Vienne peu après son passage à l'Ouest, Ligeti avoue avoir quitté la Hongrie pour s'émanciper non seulement du réalisme socialiste imposé par les Soviétiques, mais aussi de la clique conservatrice réunie autour de Kodály ${ }^{34}$. En un mot, l'intérêt croissant pour la Deuxième école de Vienne et la prise de distance avec la Nouvelle école hongroise sont deux faces d'une même médaille.

Ligeti se souvient ensuite d'avoir obtenu, au cours de l'année 1952, la Philosophie der neuen Musik de Theodor W. Adorno ${ }^{35}$. On peut mesurer l'impact du livre d'Adorno sur la pensée musicale de Ligeti en revenant sur quelques points extraits de «Megjegyzések ». Quand Ligeti soulève le problème du nivellement du contraste musical dans la musique de Schönberg, il touche au phénomène d'indifférence des intervalles harmoniques et mélodiques qu'Adorno avait déjà énoncé dans son ouvrage ${ }^{36}$. Quant à la dissociation du temps du phénomène sonore, Adorno insiste sur le fait que celle-ci est précisément l'un des rares points de convergence entre la musique de Stravinsky et l'œuvre tardive de Schönberg 37 .

Tandis que Ligeti assimile l'ouvrage d'Adorno, les premiers signes de l'influence de la pensée dodécaphonique se manifestent dans son travail de

Les Temps modernes $2, n^{\circ} 22$ (1947): 729, après des cuvres aussi impressionnantes que les deux sonates pour violon et piano ou les troisième et quatrième quatuors à cordes, Bartók aurait dû adopter nécessairement la méthode dodécaphonique de Schönberg. Or, faute de courage ou de vision, Bartók revient à la facilité d'un classicisme démodé et à l'impureté stylistique d'une musique soi-disant moderne et pourtant paré des éléments de la musique populaire.

32Ligeti, «Zwölftonmusik oder " Neue Tonalität" ? ", 45.

33Ligeti, « Járdányi Pál és Szervánszky Endre fuvolaszonatinái » [Les Sonatines pour flûte de Pál Járdányi et d'Endre Szervánszky], Uj zenei szemle 5, n 12 (1954) : 27.

34Lettre inédite de Ligeti à John S. Weissmann, écrite à Vienne le 25 janvier 1957. Cette lettre fait partie de la correspondance complète entre Ligeti et Weissmann (1957-71) qui se trouve dans la collection György Ligeti à la Fondation Paul Sacher.

35Conversation de l'auteur avec Ligeti, Hambourg, 23 septembre 1991. Outre le livre d'Adorno, Ligeti a aussi reçu Doktor Faustus de Thomas Mann à la même époque. À cet égard voir Wolfgang Burde, György Ligeti : eine Monographie (Zürich : Atlantis, 1993), 43. Que Ligeti ait pu obtenir ces deux livres moins de cinq ans après leur publication (Doktor Faustus est paru à Stockholm chez Bermann Fischer Verlag en 1947 et la Philosophie a été publié en Allemagne en 1948) est tout à fait remarquable étant donné sa situation à l'est du rideau de fer.

36Theodor W. Adorno, Philosophie der neuen Musik (Frankfurt am Main : Suhrkamp, 1976), 64.

37Ibid., 62. 
composition. De Musica ricercata (1951-53), Ligeti écrira dans une lettre de janvier 1957 que l'œuvre est une suite de 11 pièces expérimentales faites de différentes combinaisons de 2 à 12 notes. Il insiste sur le fait que l'œuvre ne contient pas de séries dodécaphoniques comme telles ${ }^{38}$. Son insistance indique que sa réflexion critique sur la méthode de Schönberg pourrait bien avoir influencé la conception de cette œuvre. Le sujet de la $11^{\mathrm{e}}$ pièce est révélateur en ce sens qu'il emploie le total chromatique sans répétition.

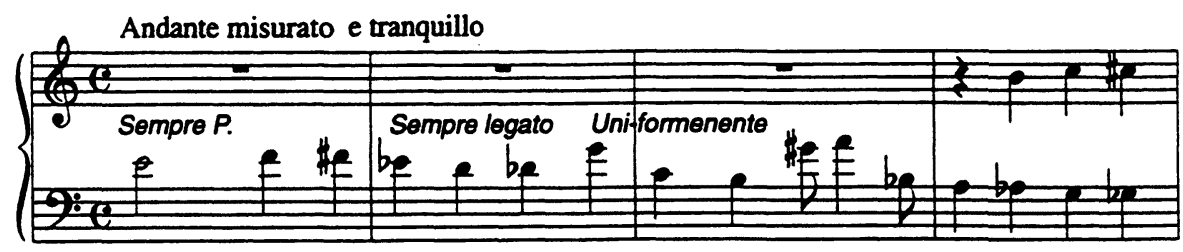

Exemple 1: György Ligeti, Musica ricercata : XI, mes. 1-4. Reproduit avec la permission de B. Schott's Söhne, Mayence.

Plus explicite encore est le canon du Quatuor à cordes no 1 (1953-54), à la section marquée FF, « Molto espressivo, poco meno mosso ». L'organisation diastématique suit l'échelle chromatique descendante pour que le déroulement des hauteurs rappelle la technique dodécaphonique.

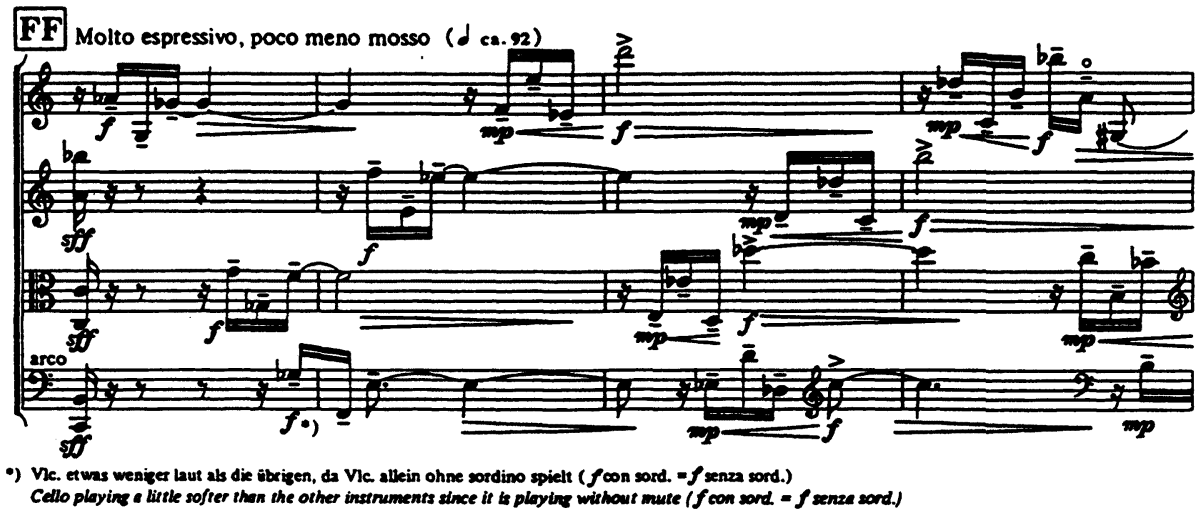

Exemple 2: Quatuor à cordes $n^{0} 1$ (« Métamorphoses nocturnes »), mes. 726-29. Reproduit avec la permission de B. Schott's Söhne, Mayence. Sacher).

38Lettre de Ligeti à Weissmann, Vienne, 25 janvier 1957 (collection György Ligeti, Fondation Paul 
Enfin, dès 1955, l'isolement forcé de la communauté culturelle hongroise se relâche quelque peu. Ce changement a un impact presque immédiat sur Ligeti. Ainsi, durant les années 1955-56, il peut entendre en concert ou sur disque certains quatuors à cordes de Bartók, qu'il n'avait pu encore écouter, ainsi que les troisième et quatrième quatuors de Schönberg, le Quatuor, op. 5, de Webern ${ }^{39}$ et la Suite lyrique de Berg ${ }^{40}$. Le contrôle de l'état sur la correspondance personnelle est aussi moins strict, ce qui permet à Ligeti d'entrer en contact avec Herbert Eimert et Karlheinz Stockhausen à Cologne. De ces derniers, ainsi que d'Otto Tomek de l'Universal Edition à Vienne, il reçoit des lots de livres, d'articles et de partitions. Il dira plus tard qu'il a ressenti l'arrivée de cette information comme une libération ${ }^{41}$. Entre autres, il reçoit en 1955 l'Introduction à la musique de douze sons de René Leibowitz ${ }^{42}$ et les deux volumes de l'Anleitung zur Zwölftonkomposition de Hans Jelinek ${ }^{43}$. Ce dernier ouvrage, une des premières méthodes pédagogiques sur la musique dodécaphonique, a une influence rapide et manifeste sur la technique de composition de Ligeti. Dès la seconde moitié de 1955, il commence une série d'œuvres utilisant ce qu'il appelle une technique sérielle non orthodoxe ${ }^{44}$. À l'exception de la Chromatische Fantasie pour piano (1956), toutes ces œuvres sont restées inachevées ${ }^{45}$. Ces expériences lui permettent de conclure que la méthode dodécaphonique ne lui convient pas en tant que technique d'écriture. Du moins, il n'y reviendra plus. Sur le plan conceptuel, par contre, sa réflexion sur les implications théoriques de la méthode de Schönberg aura des répercussions considérables sur son développement futur.

À partir de 1955-56, cette réflexion se concentre sur l'œuvre d'Anton Webern. Dans une lettre écrite à Veress quelques semaines après son arrivée à Vienne, Ligeti confie que depuis quelque temps il a été fortement influencé par Webern ${ }^{46}$. Un mois plus tard, dans une lettre à Weissmann, Ligeti précise que

39Griffiths, Ligeti, 22.

40Conversation avec Ligeti, Hambourg, 23 septembre 1991.

41 Ursula Stürzbecher, Werkstattgespräche mit Komponisten (Cologne : Hans Gerig, 1971), 37.

42Conversation avec Ligeti, Hambourg, 23 septembre 1991. Cette information a été confirmée dans une lettre de Ligeti à l'auteur, datte du 17 novembre 1991.

43Griffiths, Ligeti, 23.

44Dans l'introduction d'un curriculum vita prepare pour Weissmann peu avant son émigration de la Hongrie (collection György Ligeti, Fondation Paul Sacher), Ligeti Ecrit : « Au début, mes compositions ont ete influenctes principalement par Bartokk, Stravinsky et la musique folklorique hongroise et roumaine. J'ai toujours cherche des modes nouveaux d'expression, et, depuis trois ans, je travaille avec un type " $d$ 'architecture en montage " et une forme statique. Actuellement dans mes compositions (deux cuvres pour orchestres, Visions et Variation, ainsi que des pièces pour piano), ces techniques antérieures ont $t \in$ combinés avec une technique sérielle non orthodoxe. »

45Dans un appendice à son catalogue d'œuvres II, Nordwall, Ligeti, 201, présente une liste de sept œuvres inachevées importantes, dont six ont été commencées durant les années 1955-56. Un examen des esquisses de ces cuvres permet de constater qu'au moins trois de celles-ci font appel à une technique sérielle : Istar pokoljárása [Voyage d'Istar en enfer], oratorio pour solistes, chceur et orchestre (1955-56) ; Fehér és fekete [Blanc et noir], pour piano (1955-56) et Variations concertantes pour orchestre de chambre (1956).

46Lettre de Ligeti à Veress, Vienne, 25 décembre 1956 (collection Sándor Veress, Fondation Paul Sacher). La traduction de cette lettre a pu être effectúe grâce à une subvention à la recherche accordée par la Faculté des études supérieures et de la recherche de l'Université de Moncton. 
depuis un an et demi (c'est-à-dire juillet 1955) il se trouve « sous l'influence de la musique de douze sons (particulièrement celle de Webern) $\gg{ }^{47}$. Il revient sur ce point dans une lettre écrite environ un an plus tard, notant que, depuis qu'il a terminé son quatuor à cordes, il est tombé sous l'influence de Webern. Faisant référence à Apparitions, il remarque que cette partition ne porte guère de trace de Bartók ou de Webern, bien qu'on puisse toujours « sentir » sa grande admiration pour ces deux compositeurs, ainsi que pour certaines œuvres de Stravinsky ${ }^{48}$. On peut ainsi conclure que la période allant de la seconde moitié de 1955 jusqu'au début des années 60 marque le point fort de sa confrontation avec les œuvres du compositeur viennois.

Comme Ligeti le suggère lui-même dans sa correspondance, nous pensons que son style personnel, exemplifié par des œuvres telles Apparitions et Atmosphères, est issu des éléments de l'héritage bartókien et de la pensée dodécaphonique. Ligeti effectue cette synthèse en regard d'une démarche conceptuelle qu'il attribue à Bartók et qu'il présente dans « Megjegyzések ». D'une part, il déclare que l'avènement de l'atonalité et de la technique dodécaphonique représente une évolution conditionnée par la logique implacable de la transformation historique du matériau musical ${ }^{49}$. De l'autre, il présente la tonalité chromatique de Bartók (définie par Lendvai) comme une résolution dialectique des contradictions inhérentes à cette transformation. Selon Ligeti, Bartók réunit des aspects de la tonalité fonctionnelle traditionnelle à des aspects de la méthode dodécaphonique dans une synthèse personelle plus évoluée.

Après avoir expliqué la nécessité historique de la tonalité chromatique de Bartók, Ligeti termine son article en rejetant l'imitation directe de son style. Les dernières phrases de son article ont la résonance d'un manifeste personnel et ne sont en effet rien moins qu'un désaveu public de la Nouvelle école hongroise.

De notre courte esquisse, il ressort que le système chromatique de Bartókn'est pas le résultat d'une quelconque spéculation. Au contraire, il est justifié par la logique implacable de la transformation historique du matériau musical. Une question se pose : puisqu'il est la technique courante et qu'il représente le modèle de nos jours pour former le matériau musical, doit-on obligatoirement suivre ce modèle ? À cette question, la réponse est résolument non. Quiconque imite les principes bartókiens du maniement du matériau adopte automatiquement le style de Bartók, et le style bartókien sans le contenu bartókien devient une caricature vide et agaçante. Chaque vraie déclaration

47Lettre de Ligeti à Weissmann, Vienne, 25 janvier 1957 (collection György Ligeti, Fondation Paul Sacher).

48Lettre de Ligeti à Weissmann (collection György Ligeti, Fondation Paul Sacher). La lettre n'est pas datée, mais une référence à un prochain concert d'Artikulation le 25 mars 1958 indique qu'elle a été Ecrite avant cette date. L'admiration de Ligeti pour la musique de Webern ne constitue nullement une contradiction avec son attitude critique vis-à-vis de la méthode de Schönberg. Aussi bien dans sa lettre à Veress que dans sa première lettre à Weissmann, Ligeti insiste sur le fait qu'il n'a aucune intention de faire école avec les partisans de Webern (référence à Boulez et à Stockhausen).

49 Ce faisant, Ligeti adopte l'interprétation historique du développement du matériau musical d'Adomo. 
trouve sa propre forme d'expression et chaque nouvelle forme expressive fait évoluer la technique de composition ${ }^{50}$.

En concluant ainsi, Ligeti abandonne sa dépendance à l'égard de l'héritage bartókien. Trois ans plus tard, il précise sa propre pensée musicale dans «Wandlungen der musikalischen Form » (écrit en novembre-décembre 1958), qui commence là où l'article de 1955 s'achève, en ce sens qu'il reprend l'idée d'une relation réciproque entre technique et fantaisie ${ }^{51}$. Largement commenté dans la littérature sur Ligeti, ce document est à la fois une formulation nouvelle et un prolongement de l'article de 1955. Ainsi, Ligeti reprend des points de sa critique de la méthode dodécaphonique exposée en 1955, formulée maintenant en fonction de la musique sérielle (c'est-à-dire le problème du nivellement de contrastes ${ }^{52}$ et de la dissociation du temps du phénomène sonore ${ }^{53}$ ). Cette critique contient aussi la prédiction que la musique sérielle subira le sort des musiques antérieures puisque les germes de sa destruction future s'y élaborent déjầ 54 .

Ligeti propose ensuite sa vision de la musique dite statique, qui nous vaudra toute la série de chefs-d'œuvre composés durant les années 60 . Observant que la technique sérielle mène à des suites d'agrégrats constitués systématiquement des 12 demi-tons, il note que le rôle structurel joué par les intervalles est presque nul tandis que les qualités de masses sonores (densité, débit, ambitus) sont désormais garantes de l'intérêt musical. Or, selon lui, ce sont justement ces paramètres qui échappent au contrôle du compositeur à cause de la généralisation du phénomène sériel aux durées, aux attaques et aux intensités ${ }^{55}$. Face à

50 « Látható e rövid vázlatból is, hogy Bartók kromatikus rendszere nem holmi spekuláció eredménye, hanem a zenei anyag történeti átalakulásának az elōzményekböl szinte vaslogikával keletkezett következménye. Felvetơdik a kérdes : ha ez a mai technika, a zenei anyag megformálásának korszenú módja, akkor vajon mindenkinek a bartóki szerkesztesmódot kell-e követnie ? Erre a kérdésre határozottan “ nem " a válasz. Aki lemásolja Bartók anyagkezelési elvét, önkentelenül stílusát is átveszi és a bartóki mondanivaló nélkül üres, bántó epigonízú vázzá sápad. Minden igazi mondanivaló megtalálja kifejezési formáit, Es minden új kifejezési forma tovább viszi a zenei szerkesztés technikaját is. "Ligeti, « Megjegyzések », 44. On notera que Leibowitz, Introduction à la musique de douze sons (Paris : Arche, 1949), 161, formule une idée similaire en ce qui concerne la nouveauté et la technique dans le développement de Schönberg : « Force nous est donc de constater une nouvelle fois que le génie de Schönberg découvre, avec chaque nouvelle idée musicale, l'expression dodécaphonique la plus adéquate de cette idée. »

51 « Technik und Phantasie verändern sich in ständiger Wechselbeziehung ; jede handwerkliche Neuerung fermentiert das ganze geistige Gefüge, und jede Veränderung dieses Gefüges bedingt fortwährende Revision der kompositorischen Verfahren. " Ligeti, "Wandlungen der musikalischen Form », Die Reihe, $\mathrm{n}^{0} 7$ (1960) : 14.

52Ibid., 9. Dans une note, Ligeti renvoie ce point explicitement à la Philosophie der neuen Musik d'Adomo.

53 Ibid., 15.

54Ibid., 13.

55 Voir la phrase, souvent citee, de son analyse de Structures la de Boulez, dans laquelle il compare la généralisation de la série à tous les paramètres de composition à une prison qu'on se bâtit soi-même ; Ligeti, « Entscheidung und Automatik in der Structure Ia ", Die Reihe, $\mathrm{n}^{\circ} 4$ (1958) : 38. Robert Piencikowski, «Le Concerto de Chambre de Ligeti », Inharmoniques 2 (1987) : 215-16, note que cette analyse est déformé du fait que « la grille de lecture qui est appliqué à l'œuvre analysєe est révelatrice davantage de préoccupations de son auteur que de l'objet de son investigation. » 
cette situation, il propose que l'attention du compositeur soit directement portée vers ces qualités.

Dans « Wandlungen der musikalischen Form », Ligeti présente sa musique constituée de masses sonores comme une résolution des problèmes inhérents à la musique sérielle. Il adopte ainsi une position analogue à celle qu'il avait attribuée à Bartók dans son article de 1955. Or, dans ses propres œuvres de cette époque, Ligeti a déjà tourné son attention vers le maniement de masses sonores. Éjszaka, reggel [Nuit, matin] (1955) est constitué uniquement d'une succession de masses sonores. Ce qu'il propose dans « Wandlungen der musikalischen Form » est ainsi déjà présent de façon rudimentaire dans ses œuvres à partir de 1955 et aurait pu être décrit dans « Megjegyzések ». Cependant, pour des raisons liées au contexte politique et culturel de la Hongrie, la proposition d'une musique dite statique et constituée de masses sonores aurait senti le soufre en 1955.

Sur le plan technique, la micropolyphonie est l'une des manifestations possibles de cette musique dite statique. L'exemple type, souvent cité, est le canon d'Atmosphères (exemple 3). D'un point de vue diastématique, le sujet canonique consiste en une échelle chromatique descendante qui couvre deux octaves. Il peut être subdivisé en six fragments de quatre demi-tons, organisés en deux motifs diastématiques. Le canon est à 48 voix et en miroir. Les violons I et II, qui sont subdivisés en 28 voix individuelles, jouent le sujet à l'endroit tandis que les altos et les violoncelles, subdivisés en 20 voix, le jouent à l'envers. Le canon est à l'unisson et la distance d'entrée est irrégulière.

Au début de la section, les 48 voix entrent simultanément de manière à ce que toutes les hauteurs du sujet soient constamment présentes. La frontière traditionnelle entre mélodie et harmonie est levée. À leur place se trouve une collection d'intervalles dans un ordre précis. Le sujet est devenu un principe d'organisation diastématique qui fonctionne en quelque sorte comme une série dodécaphonique. Puisque le compositeur contrôle le déroulement rythmique, il peut orienter finement les composantes de la masse sonore (densité, vélocité, ambitus, etc.). Dans l'exemple présenté plus haut, nous pouvons percevoir les irisations sonores au moyen de la manipulation rythmique du sujet canonique. Ligeti arrive ainsi non seulement à créer mais aussi à contrôler des masses sonores qui, du point de vue de la couleur de son, deviennent mobiles et malléables.

On trouve un procédé canonique analogue dans la deuxième pièce d'Ejszaka, reggel (exemple 4). Ici le sujet est diatonique (l'échelle de mi majeur). Comme dans Atmosphères, il se découpe en deux motifs correspondants de quatre hauteurs chacun. Le canon est à sept voix, à l'unisson, et la distance d'entrée à deux mesures est régulière pour les cinq premières voix. Toutes les hauteurs ne sont jamais présentées simultanément. Par contre, à partir de l'entrée de la septième voix, un agrégat de six hauteurs est maintenu, dont la hauteur manquante change de mesure en mesure. Le déroulement de la structure canonique s'efface dans une masse sonore d'une manière analogue à ce que nous avons pu constater dans Atmosphères. 
(3) (4i)

(45)

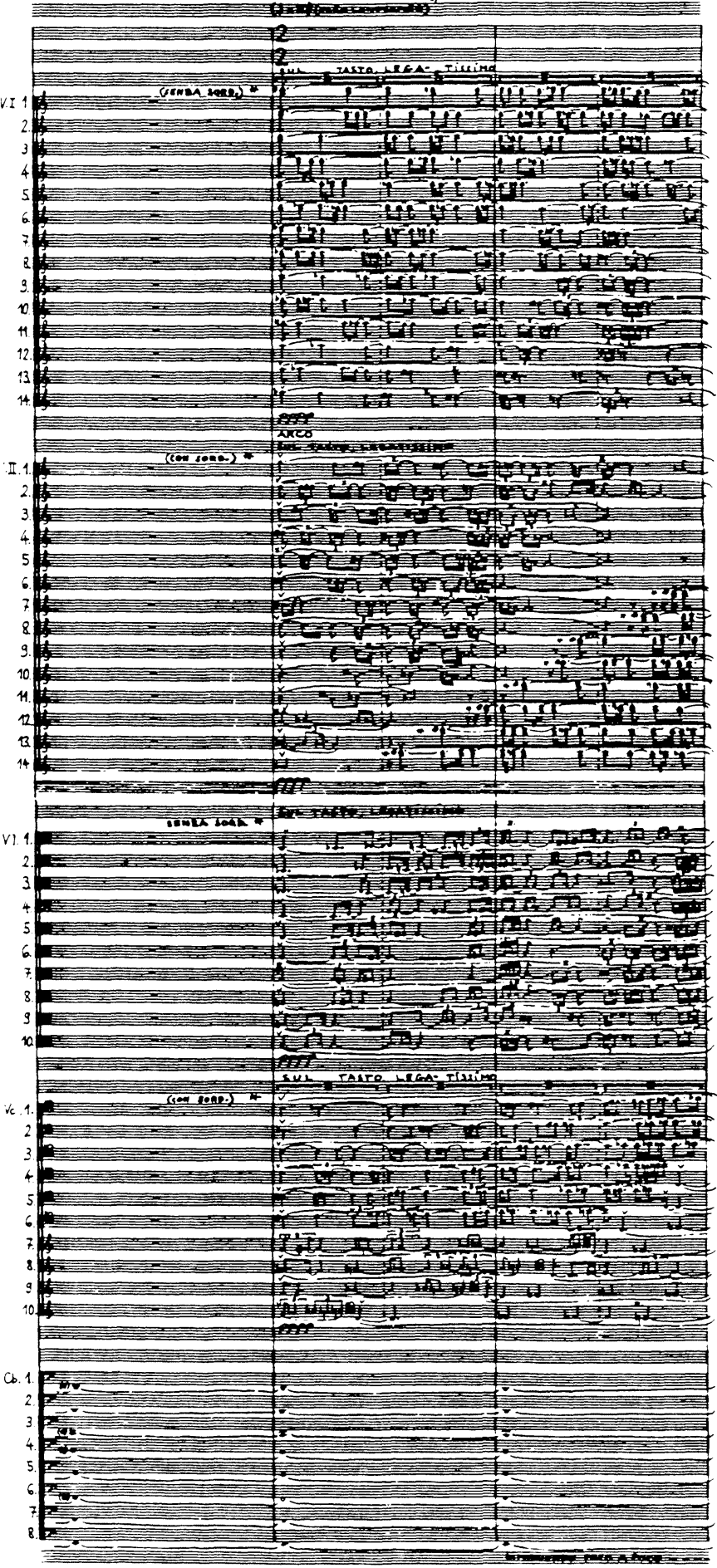

Exemple 3: Atmosphères, mes. 44-47. Reproduit avec la permission d'Universal Edition, Vienne. 


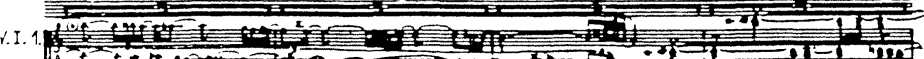

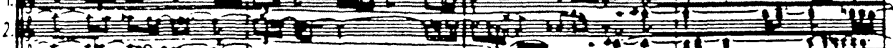

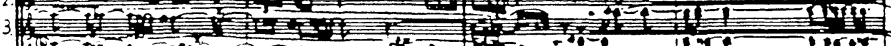
4 I

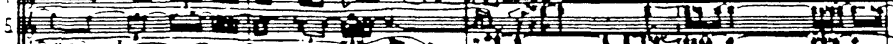

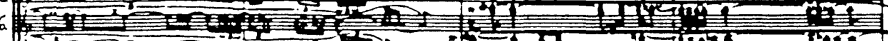

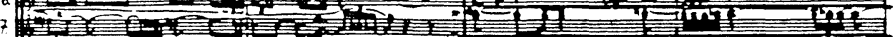

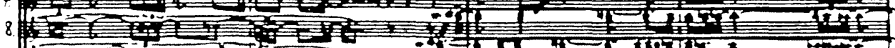

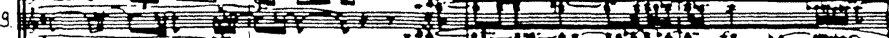

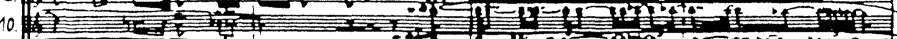

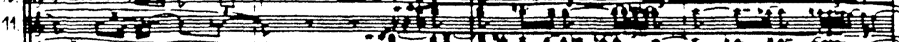
12.

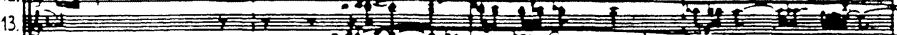

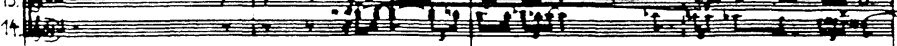
(2)

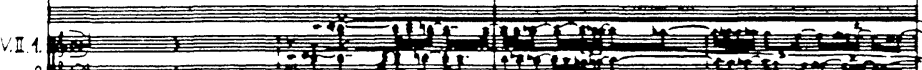
2 年

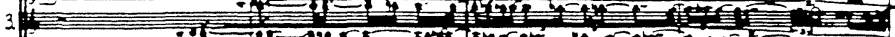

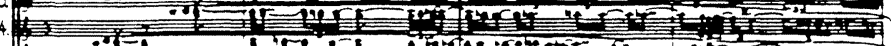
Fil 4 ID

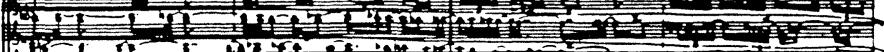

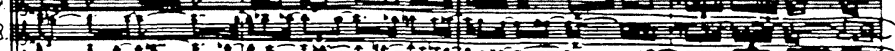

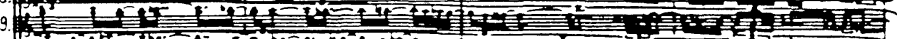

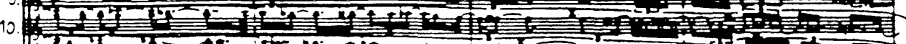

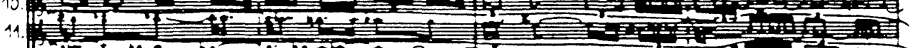

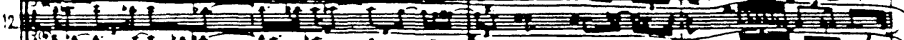
13 年 14.

ท.1. 2 I

30

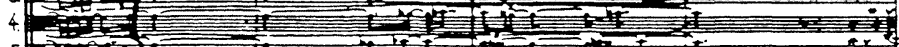

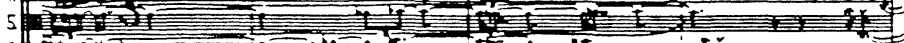

$6 \mathrm{x}^{2}$

7 (1) 8.

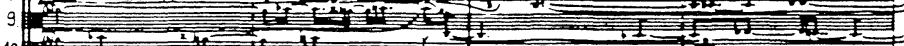
10011012 $0 \mathrm{CO}=\mathrm{CO}$

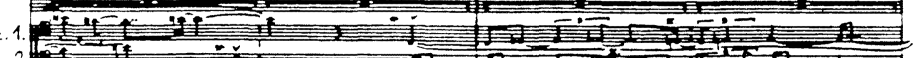

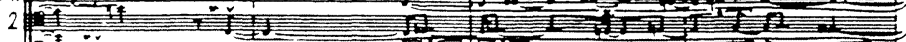

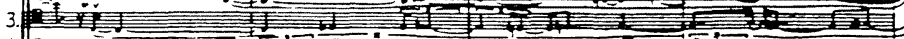
4 年

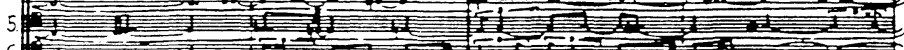

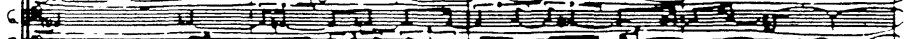

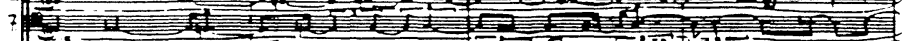

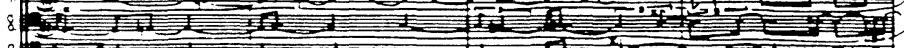

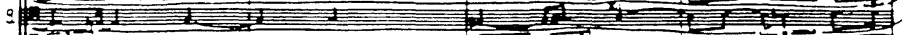

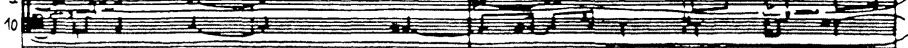
2 (1)

C.1.

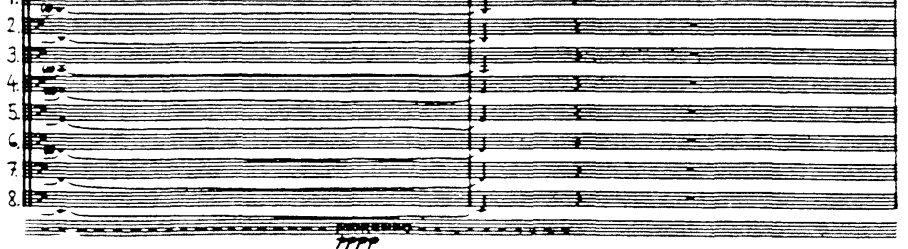


Più mosso $d=138$ (prestissimo)

(23) molto leggiero

PP sotto voce
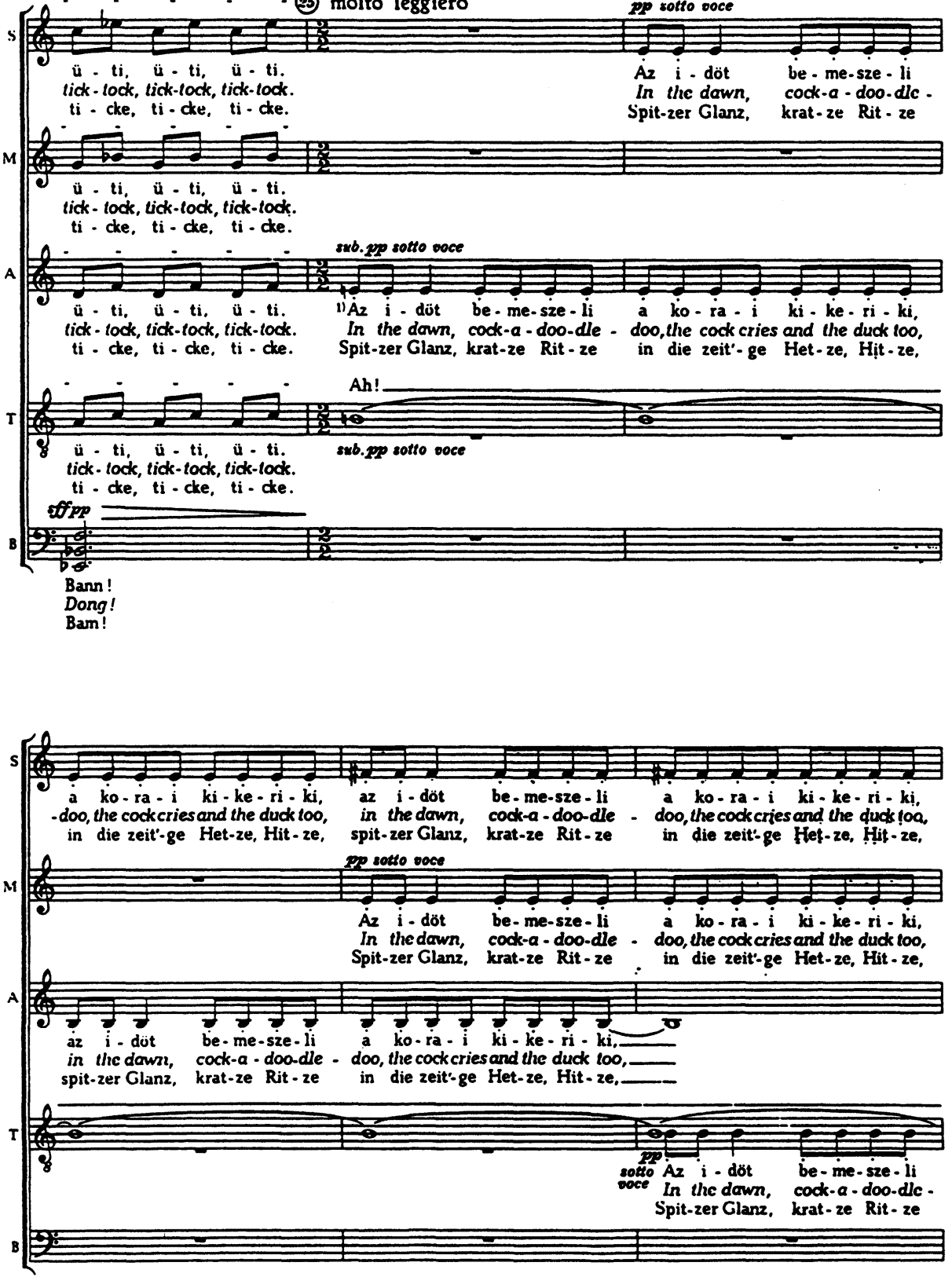

Exemple 4: Reggel, mes. 24-35. Reproduit avec la permission de B. Schott's Söhne, Mayence. 


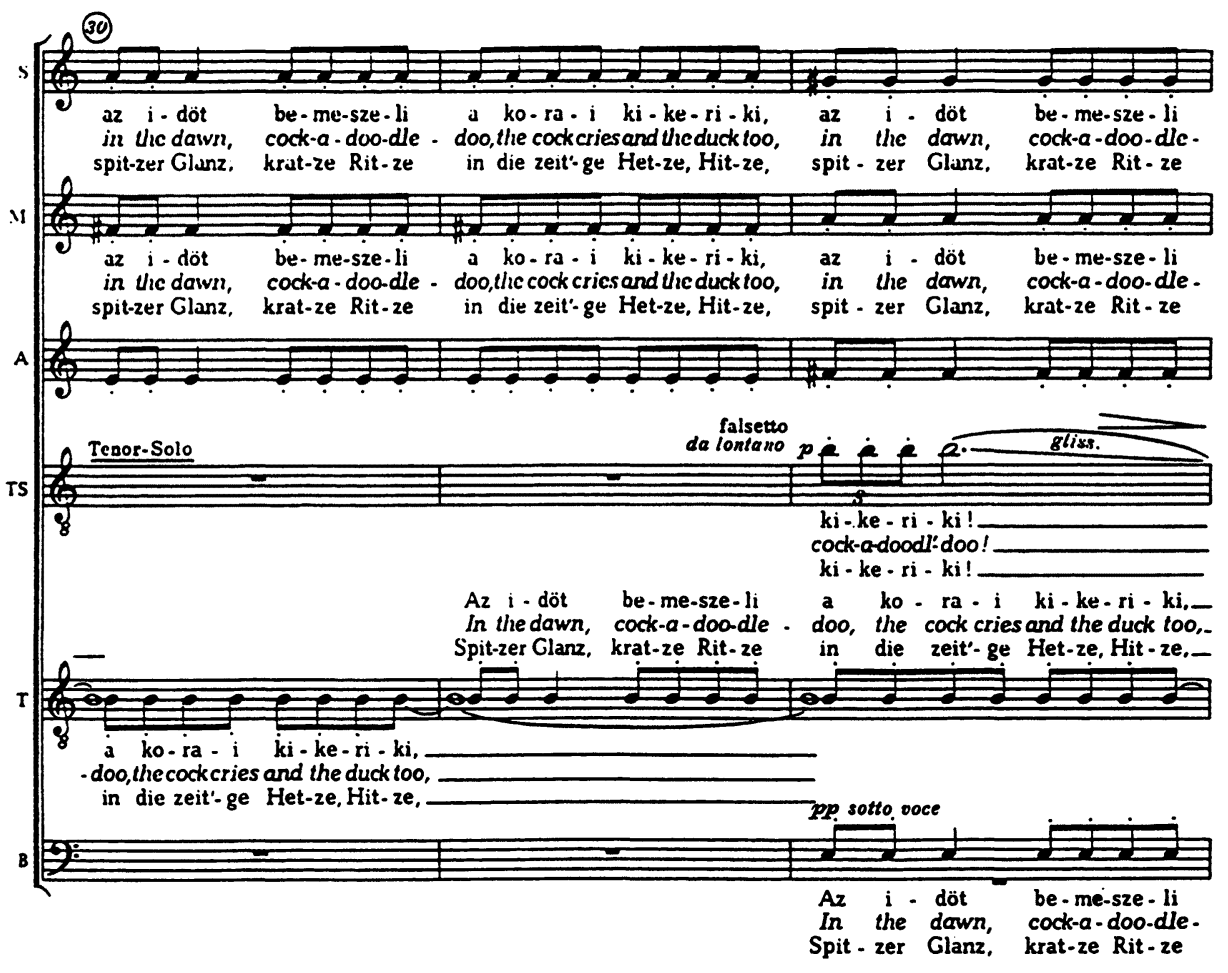

(3)

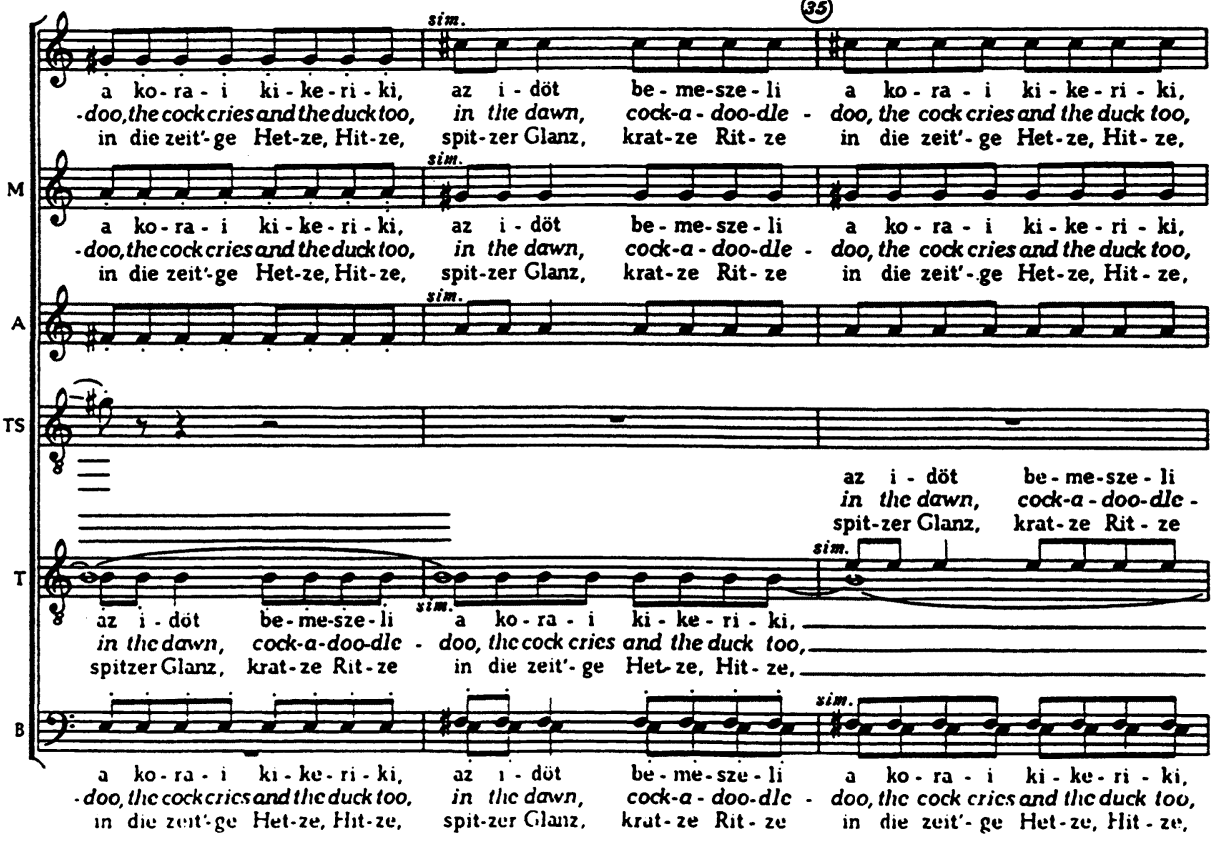


Ainsi, sur trois points précis, nous constatons chez Ligeti une continuité au-delà de son émigration en décembre 1956 : (1) une position critique vis-à-vis de la technique dodécaphonique ; (2) un intérêt marqué pour la musique de Webern ; et (3) l'exploitation de la technique de canon pour engendrer des masses sonores mobiles et malléables. Ce sont précisément les éléments de sa réflexion sur la technique de la Deuxième école de Vienne qui constituent un lien essentiel de son développement avant et après son émigration. Donc, il est faux de supposer, comme le fait Dibelius, que le départ de Hongrie marque dans tous les domaines une rupture dans l'évolution du compositeur.

En avançant cet argument nous ne voulons pas minimiser l'importance des expériences vécues par Ligeti après son arrivée à l'Ouest. Ses travaux au studio électronique du Westdeutscher Rundfunk à Cologne ainsi que ses analyses des œuvres de Boulez et de Webern, notamment, ont sans doute apporté un réel approfondissement de ses propres concepts. Néanmoins, si Michel peut parler de la "naissance d'un nouveau style " avec la composition d'œuvres telles qu'Apparitions et Atmosphères $^{56}$, nous insistons sur le fait que cette naissance suppose au moins une période de gestation. Esthétiquement, l'immaculée conception dans l'appartement de Stockhausen ou dans les studios électroniques du WDR est une pure vue de l'esprit. Isolé de l'autre côté du rideau de fer, Ligeti a su forger les concepts et les techniques nécessaire à son avenir. Fondé largement sur l'héritage de Bartók, son développement a été fécondé par une réflexion soutenue sur la Deuxième école de Vienne. Certes, ce schéma dialectique n'explique pas tout : l'apport de la musique de Stravinsky ainsi que les recherches ethnomusicologiques entreprises en 1950 restent à explorer. Néanmoins il permet de lever le voile sur une des racines principales du style ligetien.

Appendice 1 : Liste des œuvres complètes de György Ligeti écrites entre 1938 et 1956 Depuis plus de 20 ans, les catalogues I et II de l'ouvrage György Ligeti : eine Monographie d'Ove Nordwall ont été les seules sources d'information valables et facilement accessibles sur l'œuvre de jeunesse de Ligeti. Nous en avons entrepris une révision complète dans notre thèse de doctorat ${ }^{57}$ et la liste présentée ici en est extraite. La numérotation utilisée differe de celle de Nordwall pour les raisons suivantes :

(1) les deux catalogues de Nordwall ont été fondus en un seul ;

(2) seules les compositions achevées ont été inclues ;

(3) pour notre catalogue, tout changement d'instrumentation constitue une nouvelle composition. Ainsi par exemple, Musica ricercata pour piano solo et les Six bagatelles pour quintette à vent reçoivent chacune un numéro.

56Michel, György Ligeti, 39.

57Le catalogue révisé de l'œuvre de jeunesse de Ligeti sera présenté, dans sa totalité, en appendice à notre thèse de doctorat qui sera publiée intégralement chez Studio Verlag à Cologne en 1996. 
1. Sonatina (p. quatuor) mi-minore. 1938-39

Quatuor à cordes

2. Adagio molto semplice. 1940

Violon et piano

3. Kis canon egy román karácsonyi dalra [Petit canon sur un chanson de Noël roumain]. 1940

Piano

4. Kis zongorádarabok [Petites pièces pour piano]. 1939-41

Six pièces pour piano

5. Choral. 1941

Chceur mixte à quatre voix a cappella

Texte : Daniel Berzsenyi

6. Kineret [Galilée]. 1941

Mezzo-soprano et piano

Texte : Rachel Blovstein, traduit de l'hébreu en hongrois par Hubert Adler

7. [Quatre petites pièces pour piano]. 1941

8. Chorlied nach Goethe. 1942

Chcur mixte à quatre voix a cappella

Texte : Johann Wolfgang von Goethe

9. Kis zongoratrió [Petit trio avec piano]. 1941-42

Violon, violoncelle (ou alto) et piano

10. Nocturne. 1942

Piano

11. Tréfás induló [Marche drôle]. 1942

Piano à quatre mains

12. Órbán [Dans le temps]. 1942

Chour de femmes à quatre voix a cappella

Texte : Sándor Petőfi

13. A varró lányok [Les ccuseuses]. 1942

Chour de femmes à trois voix a cappella

Texte : János Arany

14. Kis tréfa [Petite farce]. 1943

Piano

15. Allegro moderato. Vraisemblablement 1943

Piano

16. Együgyú melódia [Mélodie simple]. 1943

Trois pianos

17. Polifon gyakorlat [Etude polyphonique]. 1943

Piano à quatre mains

18. Temetés a tengeren [Funéraille en mer]. 1943

Chcur mixte à quatre voix a cappella

Texte : Endre Ady 
19. Goethe Lied. 1943

Voix et piano

Texte : Johann Wolfgang von Goethe

20. Arietta. 1943

Violon (ou violoncelle) et piano

21. Præclassica (egy choraltéma három variációval) [un thème choral avec trois variations]. 1943

Orchestre de chambre

22. Cantata $n^{\circ} 1$, Tenebræ factæ sunt. 1944-45

Mezzo-soprano, deux chœurs mixtes à quatre voix et orchestre de chambre

23. Burját-mongol aratódal [Chanson de récolte buriate-mongol]. 1945

Chour mixte à quatre voix a cappella

Texte populaire buriate-mongol traduit en hongrois

24. Maître Pathelin. 1945

Musique de scène pour flate et piccolo, trompette, contrebasse, piano et percussion

25. Dereng már a hajnal [L'aube se lève déjà]. 1945

Chour mixte à quatre voix a cappella

Texte : Balász Fodor

26. Cantata $n^{\circ} 2$, Venit angelus. 1945

Mezzo-soprano, chœur mixte à cinq voix et orchestre de chambre

27. Ady-kórus (Az utca éneke) [Chøur d'après Ady (Chanson de la rue)]. 1945

Deux chours à quatre voix mixtes a cappella

Texte : Endre Ady

28. Három József Attila-kórus [Trois chøurs d'après Attila József]. 1945

Chœur mixte à deux et à quatre voix a cappella

Texte : Attila József

29. Ajánlás [Dédicace]. 1945

Duo sans texte pour deux voix ou chœur mixte à deux voix a cappella

30. Hegedú-czello duo [Duo pour violon et violoncelle]. 1945

31. Bicinai biciz. 1945

Sept duos pour soprano et baryton ou chœur mixte à deux voix a cappella

Texte (du quatrième duo) : Attila József

32. Erdélyi népdalok [Chansons folkoriques de Transylvanie]. 1945

Trois pièces pour deux voix ou chour de voix égales a cappella

Textes populaires hongrois de Transylvanie

33. Kis szerenád [Petite sérénade]. 1945

Orchestre à cordes

34. Valse. 1946

Piano

35. Idegen földön [Ả l'étranger]. 1945-46

Quatre pièces pour chour de femmes à trois voix a cappella

Texte : Bálint Balassa (1); textes populaires hongrois $(2,3)$; texte populaire slovaque traduit en hongrois (4) 
36. Két Balassa Bálint-kórus [Deux chœurs d'après Bálint Balassa]. 1946 Chœur mixte à cinq voix a cappella

Texte : Bálint Balassa

37. Betlehemi királyok [Les rois de Bethlehem]. 1946

Chour d'enfants à deux voix a cappella

Texte : Attila József

38. Húsvét [Pâques]. 1946

Chour d'enfants à quatre voix a cappella

Texte populaire hongrois

39. Magas kốsziklának [Du haut des rochers]. 1946

Chceur mixte à trois voix a cappella

Texte populaire hongrois

40. Magány [Solitude]. 1946

Chour mixte à trois voix a cappella

Texte : Sándor Weöres

41. Duo hegedũre és zongorára [Duo pour violon et piano]. 1946

42. Bujdosó [Errant]. 1946

Chour mixte à trois voix a cappella

Texte populaire hongrois

43. Tornyos Péter [Péter Tornyos]. 1947

Musique de scène pour voix et piano

Texte : drame hongrois de l'époque baroque d'un auteur anonyme

44. Székely tánc [Danse de Székl]. 1947

Piano

45. Ballada. 1947

Piano

46. Három Weöres-dal [Trois chansons d'après Weöres]. 1946-47

Soprano et piano

Texte : Sándor Weöres

47. Ha folyóvíz volnék [Si j'étais l'eau de la rivière]. 1947, révisé en 1953

Canon vocal pour quatre voix égales

Texte populaire slovaque traduit en hongrois

48. Kis szerenád [Petite sérénade]. 1947

Quatuor à cordes (d'après l'œuvre du même titre pour orchestre à cordes, voir $\mathbf{n}^{0} 33$ )

49. Due capricci. 1947

Piano

50. Invenció [Invention]. 1948

Piano

51. Nagy idôk [Grandes époques]. 1946, révisé en 1948

Chcur mixte à quatre voix a cappella

Texte : Sándor Petőfi

52. Dansuri [Danses]. 1948

Piano 
53. Dans [Danse]. 1948

Piano

54. El kéne indulni [On doit partir]. 1948, arrangement pour orchestre en 1948 par György Tornyos

Piano

55. Tavasz [Printemps]. 1948

Chœur mixte à quatre voix a cappella

Texte : poètes anonymes hongrois du XVII' siècle

56. Mifiso la sodo (Vidám zene) [Mi-fa dièse-sol la sol-do (Musique gaie)]. 1948 Orchestre

57. Nyolc kis induló [Huit petites marches]. 1948

Piano

58. Zúgva árad [Torrent]. 1948, arrangement pour fanfare en 1951 par István Sárközy et György Kurtág

Chour d'hommes à quatre voix a cappella

Texte : István Raics

59. Zúgva árad [Torrent]. 1948

Chour d'hommes à deux voix et piano

Texte : István Raics

60. Bölcôstôl a sírig [Du berceau jusqu'à la tombe]. 1948

Soprano, basse, hautbois, clarinette et quatuor à cordes

Texte populaire hongrois

61. Tánc [Danse]. 1948

Orchestre

62. Ménetdalok [Chansons de marche]. 1949

Deux voix et instruments

Texte : ?

63. Induló [Marche]. 1949

Orchestre

64. Katonatánc [Danse de soldats]. 1949

Chour à deux voix et piano

Texte : ?

65. Katonatánc [Danse de soldats]. 1949

Orchestre

66. Régi magyar társas táncok [Anciennes danses hongroises]. 1949

Orchestre à cordes avec flute et clarinette ad libitum

67. Népdalharmonizálás [Harmonisations de chansons folkloriques]. 1949

Voix et quatuor à cordes

Textes populaires hongrois

68. Kantáta az ifjúság ünnepére [Cantate pour un festival de la jeunesse]. 1949

Soprano, alto, ténor, basse, chœur mixte à quatre voix et orchestre

Texte : Péter Kuczka 
69. Festival-trombitajel [Fanfare de fête]. 1949

Trois trompettes

70. Tavaszi virág : kiserốzene [Fleur de printemps : musique de scène]. 1949 Musique pour un thêâtre de marionettes pour sept chanteurs, flûte, alto, piano et percussion

Texte : Zoltán Körmöczi d'après des contes de fées chinois

71. Három tánc cigányzenekarra [Trois danses pour orchestre tzigane]. 1949

72. Népdalfeldolgozások [Arrangements de chansons folkloriques]. 1949

Voix et piano

Textes populaires hongrois

73. Baladă şi joc [Ballade et danse]. 1950

Deux violons

74. Hajnal [Aube]. 1949-50

Trois pièces pour chœur mixte à trois, quatre et cinq voix a cappella

Texte : Sándor Weöres

75. Három József Attila-dal [Trois chansons d'après Attila József]. 1950

Soprano et piano

Texte : Attila József

76. [Deux mouvements pour quatuor à cordes]. 1950

77. Román népdalok és táncok/Cântece poporane românesti [Chansons et danses folkloriques roumains]. 1950

Mezzo-soprano, baryton et petit orchestre tzigane

Texte populaire roumain

78. Ballada és tánc [Ballade et danse]. 1950

Orchestre d'école

79. Kínai császári udvari zene [Musique pour la cour impériale chinoise]. 1950 Orchestre d'école

80. Petôfí bordala [Chanson à boire de Petôfi]. 1950

Ténor et piano

Texte : Sándor Petôfi avec traduction en allemand par J. Kretzschmar

81. Petốfi bordala [Chanson à boire de Petôfi]. 1950

Ténor et orchestre

Texte : Sándor Petőfi

82. Kállai kettổs [Danse double de Kállo]. 1950

Chour mixte à quatre voix a cappella

Texte populaire hongrois

83. Tél [Hiver]. 1950

Deux pièces pour chœur mixte à quatre et à cinq voix a cappella

Texte : Sándor Weöres

84. Négy lakodalmi tánc [Quatre danses de noces]. 1950

Trois voix de femmes ou chœur de femmes et piano

Texte populaire hongrois 
85. Lakodalmas [Danse de noces]. 1950

Chcur à quatre voix mixte a cappella

Texte populaire hongrois

86. Három lakodalmi tánc [Trois danses de noces]. 1950

Piano à quatre mains

87. [Pièce pour piano à quatre mains]. Probablement 1950

88. Szonatina. 1950

Piano à quatre mains

89. Induló és három tánc [Marche et trois danses]. 1951

Orchestre tzigane

90. Rongszônnyeg [Tapis de chiffons]. 1950-51

Trois pièces pour piano

91. Három tánc [Trois danses]. 1951

Piano

92. Grande symphonie militaire, op. 69. 1951

Piano

93. Grande symphonie militaire op. 69. 1951

Orchestre

94. Concert românesc/Román koncert [Concert roumain]. 1951

Orchestre

95. Zene egy kínai bábjátékhoz [Musique pour un thêâtre de marionettes chinoises]. 1951

Deux chianteurs et petit ensemble

Texte : Zoltán Körmöczi

96. Középlokon esik as esô [n] pleut à Középlok]. 1951

Voix et piano

Texte populaire hongrois

97. Az asszony és a katona [ $\mathrm{La}$ femme et le soldat]. 1951

Chour mixte à quatre voix a cappella

Texte populaire hongrois

98. Haj, ifjúság ! [Jeunesse !]. 1952

Chour mixte à quatre voix a cappella

Texte populaire hongrois

99. Hortobágy [Région en Hongrie]. 1952

Chœur mixte à quatre voix a cappella

Texte populaire hongrois

100. Menyasszony, vôlegény ; Dudanóta [Fiancée, fiancé ; Chant de cornemuse].

$1952 ; 1949$, révisé en 1952

Voix et piano

Texte populaire hongrois

101. Öt Arany-dal [Cinq chansons d'après Arany]. 1952

Soprano et piano

Texte : János Arany 
102. Pletykázó asszonyok [Les commères]. 1952

Canon vocal pour quatre voix égales

Texte : Sándor Weöres

103. Musica ricercata. $1951-53$

Onze pièces pour piano

104. Ricercar. Omaggio a G. Frescobaldi. 1953

Orgue

105. Hat bagatell fúvósötöre [Six bagatelles pour quintette à vents]. 1953, révisé en 1958

106. Inaktelki nóták [Chants de Inaktelke]. 1953

Chœur mixte à deux voix a cappella

Texte populaire hongrois

107. Hat inaktelki népdal [Six chansons folkloriques de Inaktelke]. 1953

Trois voix de femmes et petite orchestre

Textes populaires hongrois

108. Pápainé. Népballada vegyeskarra [Madame Pápai. Ballade folklorique pour chour mixte]. 1953

Chœur mixte à quatre voix a cappella

Texte populaire hongrois

109. Szonáta (Dialogo e capriccio). 1948-49 (Dialogo) ; 1953 (Capriccio)

Violoncelle

110. Métamorphoses nocturnes. 1953-54, révisé en 1958

Quatuor à cordes

111. Mátraszentimrei dalok [Chansons de Mátraszentimrei]. 1955

Chœur d'enfants ou de femmes à deux et à trois voix a cappella

Textes populaires hongrois

112. Éjszaka, reggel [Nuit, matin]. 1955

Chœur mixte à huit voix a cappella

Texte : Sándor Weöres

113. Chromatische Phantasie. 1956

Piano

114. Viziók [Visions]. 1956 (première version du premier mouvement d'Apparitions)

Orchestre

Appendice 2 : Bibliographie des articles, des recensions et des publiés par György Ligeti avant 1957

Durant l'automne 1994 nous avons étudié systématiquement la correspondance de Sándor Veress, conservée à la Fondation Paul Sacher ; au cours de celle-ci un article écrit par Ligeti intitulé « Von Bartók bis Veress : Neues aus Budapest » a pu être répertorié $^{58}$. L'article de Ligeti n'est mentionné dans aucune bibliographie de ses

58 Cet article est mentionné dans une lettre de Miklos Weiss (directeur de la maison d'édition musicale Cserépfalvi), Budapest, 31 mars 1949. La correspondance volumineuse entre Veress et Weiss (1949-51), 
écrits. Il est intéressant d'abord parce qu'il témoigne de l'estime que l'étudiant portait à son professeur de composition, ensuite parce qu'il permet de mieux saisir l'horizon musical de Ligeti au moment où il a quitté l'Académie Franz Liszt. Avec une assurance rappelant celle du jeune Boulez, Ligeti brosse rapidement un tableau de la scène musicale à Budapest pendant la saison 1947-48.

« Kótaismertetések » [Revue de partitions], Zene-pedagógia 2, nº 3 (1948) : 43.

« Bartók : Medvetánc (1908) (Elemzés) » [Bartók : Danse de l'ours (1908) (Analyse)], Zenei szemle 5 (1948) : 251-55.

« Gát József : Kottaolvasás » [József Gát : lecture de partitions], Zenei szemle 5 (1948): 257.

«Österreichische Musikzeitschrift », Zenei szemle 5 (1948) : 284-85.

« Kották » [Partitions], Zenei szemle 6 (1948) : 337.

« Neue Musik in Ungarn », Melos 16, $\mathrm{n}^{\circ} 1$ (1949) : 5-8.

« Neues aus Budapest : Von Bartók bis Veress », Melos 16, nº 2 (1949) : 60-61.

« Béla Bartók Werk » [catalogue d'œuvres assemblé par Erich Doflein et revisé par Ligeti], Melos 16, $\mathrm{n}^{0} 4$ (1949) : 153-55.

« Szervánszky Endre : Vonósnégyes. (M. Mũvészeti Tanács kiadása) » [Endre Szervánszky : Quatuor à cordes. (paru chez M. Mũvészeti Tanács)], Zenei szemle (1949) : 102-3.

« Járdányi Pál : Szonáta két zongorára. (M. Mûvészeti Tanács kiadása) » [Pál Járdányi : Sonate pour deux pianos. (parue chez M. Mưvészeti Tanács)], Zenei szemle (1949): 103.

« Sugár : Vonóstrió. (A Magyar Mũvészeti Tanács kiadása) » [Sugár : Trio à cordes. (paru chez Magyar Mvészeti Tanács)], Zenei szemle (1949) : 105-6.

« Neues aus Budapest : Zwölftonmusik oder “ Neue Tonalität” ? ", Melos 17, $\mathrm{n}^{0} 2$ (1950) : 45-48.

« Népzenekutatás Romániában » [Recherche ethnomusicologique en Roumanie], Ujj zenei szemle $1, \mathrm{n}^{\circ} 3$ (1950) : 18-22.

« Egy aradmegyei román együttes » [Un ensemble folklorique roumain du district de Arad], dans Kodály Emlékkönyv. Zenetudományi Tanulmányok I. [Kodály Festschrift. Études musicologiques I], éd. par Dénes Bartha et Bence Szabolcsi (Budapest : Akadémia Kiadó, 1953), 399-404.

Klasszikus összhangzattan [Harmonie classique] (Budapest : Zenemúkiadó, 1954).

« Járdányi Pál és Szervánszky Endre fuvolaszonatinái » [Sonatines pour flûte de Pál Járdányi et de Endre Szervánszky], Új zenei szemle 5, no 12 (1954) : 26-28.

« Megjegyzések a bartóki kromatika kialakulásának egyes feltételeirōl » [Remarques sur les conditions du développement du chromaticisme bartókien], Uj zenei szemle 6 , no 9 (1955) : 41-44.

A klasszikus harmóniarend I-II [Le système de l'harmonie classique] (Budapest : Zenemúkiadó, 1956).

donne un éclairage particulièrement intéressant de la scène musicale à Budapest dans cette période importante. 


\section{Résumé}

L'article présente certains aspects de notre thèse de doctorat intitulée « An Introduction to the Early Works of György Ligeti ». Il propose une critique de deux idées reçues et largement répandues dans la littérature sur le musique de ce compositeur : (1) en arrivant en Europe de l'Ouest en décembre 1956, Ligeti se serait départi de tout le bagage technique et stylistique qu'il avait acquis auparavant en Hongrie ; (2) avant de passer à l'Ouest, il n' aurait eu presque aucune connaissance de l'avant-garde musicale de l'Europe de l'Ouest. 